\title{
PESQUISANDO NO COTIDIANO: RECUPERANDO MEMÓRIAS DE PESQUISA EM PSICOLOGIA SOCIAL
}

\author{
Mary Jane P. Spink \\ Pontifícia Universidade Católica de São Paulo, São Paulo, Brasil
}

RESUMO: Na reação à hegemonia da Psicologia Social norte-americana, nos anos setenta e oitenta, algumas experiências de pesquisas no cotidiano foram banidas da memória coletiva da disciplina, seja por excesso de patrulhamento ideológico, seja pela identificação de toda a produção européia e norte-americana com a vertente mais individualista da Psicologia Social. Ao recuperar o interesse por observações no cotidiano, a Psicologia Social "desmemoriada" buscou na Antropologia o subsídio para pesquisas de "tipo etnográfico". O objetivo deste texto é recuperar algumas experiências de observação no cotidiano, autóctones à Psicologia Social, visando contribuir para o desenvolvimento de metodologias de observação de caráter psicossocial.

PALAVRAS-CHAVE: observação; cotidiano; métodos de pesquisa.

\section{RESEARCHING THE FLUX OF DAILY LIFE: RECUPERATING MEMORIES OF RESEARCH IN SOCIAL PSYCHOLOGY}

\begin{abstract}
In reaction to the hegemony of North American Social Psychology in the seventies and eighties, some research experiences on the flux of daily life were banned from the collective memory of the discipline because of excessive ideological patrol or due to identifying with the more individualistic trends of Social Psychology produced in Europe and North American. With the return of interest in observing quotidian life, Social Psychology, forgetting its own history, turned to Anthropology for subsidies for "ethnographic-like" research. The aim of this article is to recuperate some of the experiences of observation in quotidian life that are autochthonous to Social Psychology so as to contribute to the development of psychosocial observation research strategies.
\end{abstract}

KEYWORDS: observation; quotidian; research methods.

Creio que o título deste artigo merece algumas explicações. Primeiramente, pela ênfase em pesquisar no cotidiano, ao invés de pesquisar $o$ cotidiano. Certamente não é o significado de cotidiano que está em pauta nesse esforço de diferenciação. O termo cotidiano tem um significado bastante cristalizado em dicionários e teorizações: é aquilo que acontece diariamente; que é comum a todos os dias; é o dia-a-dia que passa desapercebido em sua mesmice a não ser para autores, como Agnes Heller (1972) e Michel de Certeau (1996), que fizeram dessa mesmice o cerne de importantes reflexões sobre a vida em sociedade. A ênfase dada ao no procura marcar a diferença na postura metodológica.

Se pesquisarmos $o$ cotidiano, estabeleceremos a clássica separação entre pesquisador e seu objeto de pesquisa. Mas, se pesquisarmos no cotidiano, seremos partícipes dessas ações que se desenrolam em espaços de convivência mais ou menos públicos. Fazemos parte do fluxo de ações; somos parte dessa comunidade e compartimos de normas e expectativas que nos permitem pressupor uma compreensão compartilhada dessas interações.

Essas diferenças sutis emergem, em parte, de posicionamentos construcionistas sobre o conhecimento, abdicando dos universais e priorizando os conhecimentos locais. Mas decorrem, também, de problemáticas enfrentadas no afã de pesquisar esses espaços fluidos que habitamos cotidianamente.

Por exemplo, estamos iniciando uma pesquisa sobre controle e uso de tabaco em espaços públicos de convivência. ${ }^{1} \mathrm{O}$ projeto prevê perambulações pelo quadrilátero em que se localiza a Pontifícia Universidade Católica de São Paulo, mapeando os locais de uso público - restaurantes, bares, livrarias e bancas de jornal - em busca de indicadores de controle do tabagismo e, paralelamente, dos usos feitos do tabaco nesses espaços. Deparamo-nos, assim, com o problema do método.

Há uma forte tentação de chamar esse tipo de pesquisa de etnografia ou de observação participante, embora haja também ciladas, uma das quais a apropriação malfeita de métodos que têm dono, como no caso da etnografia. Isso tem sido recorrente em nossa disciplina de base, a Psicologia Social. Daí a proposta de recuperar memórias de pesquisas em busca de subsídios metodológicos.

Para dar conta dessa demanda, retomamos a história da Psicologia Social com um olhar muito específico, norteado pela pergunta: como nossos ancestrais trataram a observação? De modo a poder responder à pergunta, desengavetamos três experiências de pesquisa em que a observação foi fundamental, buscando trazê-las para a contemporaneidade e, especialmente, para as tradições de pes- 
quisa autóctones, próprias ou mais conhecidas na Psicologia Social brasileira.

As três experiências datam da primeira metade do século passado. A primeira, Marienthal, é o estudo de uma comunidade austríaca que vivia, na época, os efeitos do desemprego resultante da crise financeira de 1929. Tratase de pesquisa conduzida por três psicólogos austríacos: Marie Jahoda, Paul Lazarsfeld e Hans Zeisel (2003). O paralelo contemporâneo com esse estudo será com a psicologia comunitária latino-americana.

A segunda, Quando as profecias falham, é um estudo realizado por Leon Festinger, Henry Riecken e Stanley Schachter (1956) com um grupo de pessoas que se organizaram em torno da profecia de que o mundo seria destruído por um cataclismo que ocorreria em 21 de dezembro de 1954. A pesquisa permite problematizar a observação participante, aspecto fundamental para quem quer pesquisar no fluxo dos acontecimentos diários em um espaço público delimitado.

A terceira experiência, Midwest e suas crianças, concerne ao estudo de Roger Barker e Herbert Wright (1955/ 1971), considerado precursor da Psicologia Ambiental, Realizado em 1950, busca trazer o rigor da Psicologia Social Experimental para a observação. Fornecerá, no contexto desta reflexão, o contraste necessário com métodos de observação mais contemporâneos.

\section{Marienthal e a Imaginação Metodológica}

O estudo de Marienthal é descrito por seus autores como uma sociografia de uma comunidade desempregada. Os 1.486 habitantes desse pequeno vilarejo viviam em decorrência da indústria têxtil que havia crescido a partir de um antigo moinho. A vida laboral e social dessa comunidade estava intrinsecamente ligada à fabrica e, quando suas portas se fecharam, três quartos das famílias passaram a depender de auxílio desemprego. Os autores do estudo, jovens psicólogos sociais afiliados ao partido socialista austríaco, buscavam entender o efeito do desemprego na vida familiar e social. As preparações para o estudo foram iniciadas no outono de 1931, quando uma jovem estagiária foi morar na comunidade durante seis semanas e estabeleceu contato com seus moradores.

O estudo utilizou uma variedade de táticas de coleta de dados inventadas, literalmente (pois os autores comentam a ausência de referenciais metodológicos na disciplina de base), nas freqüientes reuniões de equipe, algumas "não interferentes" - conforme expressão introduzida por Webb em 1966 (Webb, Campbell, Schwartz, Sechrest \& Grove, 1981) - e outras mais direcionadas. Entre as estratégias não interferentes, foram coletados dados quantitativos (como resultados de eleições, estatísticas populacionais, registros de empréstimos de livros da biblioteca local e assinaturas de jornais) e qualitativos (observação partici- pante de famílias, observações no ambulatório de saúde, relatos de membros da comunidade). Entre as estratégias mais direcionadas, foram aplicados testes projetivos, solicitados registros de atividades diárias e dos gastos da família. Os pesquisadores usaram, assim, uma miscelânea de métodos num estilo que, bem mais tarde, Norman Denzin (1970) chamaria de "triangulação metodológica."

Dentre as estratégias metodológicas, uma certamente seduz, a saber, escondidos estrategicamente, os pesquisadores mediram a velocidade do deslocamento da população: mulheres, ocupadas com afazeres domésticos, que andavam rápido, homens, para quem a dimensão temporal havia perdido o sentido, que andavam lentamente, parando para conversar ou simplesmente olhar o que se passava ao redor.

O livro está organizado em oito capítulos. Após uma pequena introdução que descreve os objetivos e estratégias de coleta de dados, os demais capítulos abordam os seguintes temas: a vila industrial, padrão de vida, menus e orçamentos domésticos, uma comunidade desgastada, respostas às privações, o sentido do tempo e o esgotamento da resiliência.

É uma pequena jóia que teve pouco impacto no início, tendo em vista os tempos duros que se anunciavam com a subida de Hitler ao poder. As afiliações de esquerda e a origem judaica levaram à adoção do princípio da precaução e o primeiro relatório, publicado em 1933, saiu sem os nomes dos autores. Eventualmente todos emigraram: Marie Jahoda para a Inglaterra, Lazarsfeld e Zeisel para os Estados Unidos. Nos Estados Unidos, Lazarsfeld tornouse diretor do projeto de pesquisa sobre rádio da Universidade de Princeton e ficou conhecido como importante teórico da comunicação.

Também o emergente positivismo da ciência norteamericana tornou difícil sua divulgação para além das fronteiras dos países germânicos. E por muito tempo, conta Lazarsfeld, eles não consentiram que fosse feita uma tradução do estudo para a língua inglesa: a abordagem, para a Psicologia Social norte-americana, seria considerada muito ingênua.

Nunca explicitamos nossos procedimentos amostrais e provavelmente eles não eram muito bons; nossas tipologias haviam sido desenvolvidas intuitivamente e nunca testadas quanto à consistência lógica. Não usamos escalas de atitude (...) Muitos padrões de qualidade que meus colegas e eu insistíamos em nossos ensinamentos foram negligenciados. Só posso desculpar tudo isso lembrando do pioneirismo de nosso espírito de aventura; mas me deixava desconfortável e por muito tempo recusei qualquer oferta de publicação de uma tradução (Jahoda et al., 2003, p. xxxv).

Pena, pois Marienthal é certamente uma pequena obra prima, esquecida no tempo, embora seja um retrato de uma 
época. Não apenas um retrato das dificuldades vividas por esta pequena comunidade, mas também um relato contundente de uma Psicologia Social comprometida com os problemas vivenciados pela população e, como evidenciado no posfácio metodológico, herdeira de uma rica tradição de sociografia.

É interessante notar que a abordagem dos pesquisadores foi de participar ativamente da vida da comunidade, buscando serem aceitos como membros da comunidade com funções bem claras, como organizar cursos de costura e ginástica e tratamento médico comunitário. Essa imersão nos remete aos desenvolvimentos da Psicologia Social Comunitária em nosso continente. Muitas décadas após Marienthal, certamente, mas com o mesmo espírito de pioneirismo e de preocupação com o papel social da disciplina.

\section{Interlúdio 1: A Psicologia Comunitária Latino-Americana}

A Psicologia Comunitária que se desenvolveu na América Latina a partir de 1975 adotou um modelo segundo o qual uma comunidade, trabalhando com uma equipe de psicólogos, assume o controle e as decisões acerca de uma situação que a afeta. Por exemplo, um problema de saúde, de moradia ou de recuperação de espaços de sociabilidade. Tem por princípio básico o crescimento grupal e individual, movimento que pode contar com o apoio de agentes externos e instituições públicas, governamentais ou não-governamentais, que podem atuar como promotoras de serviços, mas não como gestoras da ação. Nesse sentido, trata-se de uma Psicologia Social essencialmente política que visa à promoção da cidadania - por meio do conceito de empowerment - e tem por foco os processos de exclusão social.

Desenvolvendo-se a partir de meados da década de setenta do século vinte, une o método educacional de Paulo Freire (1974) à investigação-ação-partiapante do sociólogo colombiano Orlando Fals Borda (1981).

A pesquisa participante está, para nós brasileiros, intrinsecamente associada ao livro organizado por Carlos Brandão, com primeira edição publicada em 1981. A coletânea reuniu reflexões de Paulo Freire, Orlando Fals Borda, Rosiska Darcy de Oliveira, do próprio Brandão, assim como de equipes de comunidades de base e pastorais operárias. Trata-se de uma ressignificação política de uma forma de produção de conhecimento de domínio comum a várias disciplinas, embora talvez mais sistematizada na Antropologia.

Nesse caminho de politização, tornou-se imprescindível cindir a dicotomia entre o conhecimento científico, de acesso restrito aos iniciados, e o conhecimento popular, colocando as ferramentas de produção de conhecimento à disposição da produção coletiva. Um trabalho que, nas palavras de Brandão, "recria, de dentro para fora, formas concretas dessas gentes, grupos e classes participarem do direito e do poder de pensarem, produzirem e dirigirem os usos de seu saber a respeito de si próprias" (Brandão, 1981, p. 9). Digamos, um anti-colonialismo epistemológico.

No Brasil, a Psicologia Comunitária está associada aos nomes de Silvia Lane, Raquel Guzzo e Maria de Fátima Quintal de Freitas. Mas talvez seja Maritza Montero (1994), da Universidade Central da Venezuela, que mais esforços fez para fortalecer a rede de psicólogos comunitários latinoamericanos e sistematizar o método de ação da Psicologia Comunitária. Seu livro mais recente, publicado em 2006, chama-se precisamente Hacer para transformar: El método em la Psicologia Comunitária.

À semelhança do estudo precursor de Marienthal, Montero (1994) enfatiza o uso combinado de métodos quantitativos e qualitativos e o envolvimento necessário com a comunidade. A diferença fundamental está na noção de pesquisa-ação-participativa, modelo que, como nos referimos anteriormente, é produto do compromisso político da Psicologia latino-americana com a transformação social, numa situação pautada pela desigualdade e exclusão de grandes parcelas da população do acesso a bens e serviços. Ou seja, embora os pesquisadores de Marienthal fossem profundamente solidários e comprometidos com a situação desesperadora de desemprego na comunidade, o objetivo do estudo não era a ação de "empoderamento" da comunidade, porém o de compreensão psicossocial dos efeitos do desemprego na vida das família dessa comunidade.

Ainda a respeito de semelhança, a sociografia de $M a$ rienthal, como os atuais estudos psicossociais de comunidades, também tem sustento na observação participante. Mas será o segundo estudo por nós escolhido que possibilitará entender a moderna ressignificação dessa forma de coleta de dados.

\section{Profecias que Falham: Explorações em Observação Participante}

Este estudo, publicado em 1956, na forma de livro que se lê como romance, foi escrito por pesquisadores do Laboratório de Pesquisa sobre Relações Sociais da Universidade de Minnesota. Relata as experiências de um grupo de pessoas lideradas por uma médium e um teórico de UFOS (objetos voadores não-identificados) que aguardaram ansiosamente sua salvação perante um iminente desastre que traria o fim do mundo. O líder do estudo era Leon Festinger, o teórico da dissonância cognitiva. O ponto de partida foi o pressuposto teórico de que as pessoas, diante da des-confirmação de uma crença - momento em que se instalava a dissonância cognitiva - reagiam, exacerbando a crença, ou abandonando-a.

Na introdução, os autores comentam que é difícil encontrar episódios de des-confirmação de crenças que envolvem grupos de pessoas. Historiam vários movimentos for- 
mados com base na veiculação de profecias, mas advertem que os dados disponíveis tendem a ser pobres, com poucos detalhes das relações pessoais do grupo em questão.

Em 1954, eles tiveram conhecimento das profecias de Marian Keech e se renderam à oportunidade de acompanhar de perto a vida diária do grupo que se reuniu em torno dessa senhora e de seu principal parceiro, um médico de uma cidade vizinha que há muito reunia pessoas para discutir a possível existência de outros mundos e o contato com alienígenas, o Dr. Armstrong.

Nas 233 páginas do livro, os autores relatam o dia-adia desse grupo que, inicialmente, se dividia em duas cidades próximas a Salt Lake City, no estado de Utah, mas, à medida que se aproximava a data fatídica, passaram a conviver na casa da senhora Keech. Nesse meio tempo, convictos da aproximação do fim do mundo, muitos se desfizeram dos bens materiais ou abandonaram suas carreiras e empregos e se prepararam, por meio de reuniões de grupo, meditação e sessões mediúnicas, para a chegada dos discos voadores que salvariam os crentes da destruição.

Essas descrições densas do dia-a-dia dessas pessoas englobam cerca de quatro meses e são precedidas por uma introdução teórica com hipóteses sobre as condições para que ocorra a dissonância cognitiva e os efeitos previstos para a superação do desconforto assim produzido, e seguidas de um capítulo final que sintetiza como os diversos membros do grupo lidaram com a des-confirmação da profecia. É um belo trabalho de observação participante com sérios problemas éticos que apontaremos adiante. Mas é também produto de época e tal, como Lazarsfeld em relação a Marienthal, envolto por retóricas defensivas sobre as fragilidades do estudo diante do crescente positivismo da Psicologia Social norte-americana. Os autores acrescentam ao belo texto um apêndice metodológico que tem dupla função. De um lado, relatar a condução do estudo. De outro, problematizar aspectos que poderiam colocar o rigor metodológico sob suspeita.

Quanto à condução do estudo, surpreende o leitor contemporâneo que os observadores tenham se infiltrado no grupo, escondendo seus objetivos e identidades. Um pequeno grupo de pessoas em duas cidades próximas que se reuniam mobilizados pelo interesse comum em UFOS, passaram a formar um grupo coeso e altamente mobilizado pela profecia de fim do mundo. Participavam desse grupo dezesseis pessoas: oito vindos de Collegeville, sob a liderança do doutor Armstrong e outros oito de Salt Lake City, mobilizados pelo poder mediúnico da senhora Keech. Os pesquisadores infiltraram nesse grupo dois observadores, um homem e uma mulher, em cada um dos locais. Ou seja, além dos três pesquisadores, outros quatro, totalizando sete, acompanharam o grupo como observadores participantes.

Mas suas identidades não foram reveladas, gerando dilemas pessoais resultantes da identidade disfarçada e da necessidade de manter certas responsabilidades perante $o$ grupo. Por exemplo, quando a senhora Keech convocou um dos autores a comandar a reunião do dia 23 de novembro, a solução encontrada por ele foi de sugerir que o grupo meditasse e aguardasse inspiração. Seguiu-se um silêncio agoniado rompido apenas quando outra participante entrou em transe. Mesmo assim, duas vezes, naquela noite, a senhora Keech perguntou a ele se havia trazido alguma mensagem de seres extraterrestres.

Hoje, certamente, esse tipo de inserção seria considerado problemático. Mas, na época, o que preocupava os pesquisadores era a manutenção do status de observadores neutros. Nessas reuniões, por exemplo, havia consultas individuais com as duas médiuns do grupo e os observadores ficavam agoniados, quando deles se exigiam respostas a perguntas supostamente feitas pelos contatos do além. Há um relato em que uma das médiuns incorporou a voz do Criador e fez perguntas às quais o observador respondeu evasivamente. Mas cada resposta foi interpretada como prova de que era mesmo o Criador que se manifestava. Dizem os autores "diante desse fluxo de invenções, até mesmo a mais sofisticada técnica de resposta não diretiva se torna impossibilitada" (Festinger et al., 1956, p. 243). Referem, portanto, que, mesmo quando uma participação direta não era requisitada, a mera presença no grupo dava apoio a convicções e atividades dos demais membros do grupo. Mas dizem eles, "em nenhum momento exercemos qualquer influência nas atividades de proselitismo. Estávamos meticulosamente preocupados com esta questão e tivemos total sucesso em evitar ter qualquer impacto em nossa mais importante variável dependente" (Festinger et al., p. 243).

Um dos maiores problemas da não-revelação da identidade dos pesquisadores foi o registro das observações. Não era possível fazer anotações na presença dos membros do grupo e nem mesmo fazê-las em local privado, pois os observadores raramente ficavam a sós. Uma das estratégias foi anotar quando iam ao banheiro, mas também não era muito fácil, uma vez que idas freqüentes ao banheiro certamente suscitariam desconfiança. Também era possível fazer anotações nas pequenas saídas para tomar ar. De modo geral, porém, os observadores tiveram que confiar na memória até o momento em que pudessem ditar tais memórias para um gravador, o que implicava intervalos de cerca de três a quatro horas entre o evento e o registro. Desculpam-se, no posfácio, contrapondo a oportunidade inusitada de acompanhar de perto um movimento social, com a fragilidade decorrente da impossibilidade de utilização das técnicas quantitativas comuns à Psicologia Social da época.

\section{Interlúdio 2: Limites Éticos da Observação Participante}

Como diz o nome, a observação participante é realizada de dentro de uma dada situação. Senão como mem- 
bro nato da situação observada, pelo menos como membro aceito pelos demais partícipes.

A observação participante é uma velha ferramenta das Ciências Sociais cuja utilização inicial está fortemente associada à curiosidade ocidental em relação a um outro que é considerado exótico em relação ao habitat cultural do observador-pesquisador. Não espanta, portanto, que tenham sido os antropólogos os primeiros a sistematizar o método da observação-participante, tendo como "outro" culturas distintas das suas. O registro das observações tinha, nesses primórdios, dois objetivos. De um lado, era um meio de preservar a memória de formas de viver que seriam inevitavelmente modificadas pelo contato com culturas dominantes. No entanto, de outro lado, os registros visavam à análise das estruturas de sociabilidade que promoviam certos padrões de comportamento, permitindo que esses se tornassem compreensíveis para o olhar estrangeiro do antropólogo-pesquisador.

Esse outro-exótico, tradicionalmente localizado fora da cultura de origem do pesquisador, assumiu outra conotação na Sociologia Urbana da Escola de Chicago, em meados do século vinte (Burgess, 1982). O outro-exótico passou a se localizar na própria cultura de origem do pesquisador; em grupos marginalizados ou de menor visibilidade, como delinqüentes, médicos residentes, usuários de clínicas de aborto; grupos que estavam fisicamente próximos, embora culturalmente tão distantes quanto os aborígines dos primeiros estudos antropológicos.

Em qualquer um desses casos, assim como nos estudos comunitários da Psicologia Social, duas questões se apresentam quando falamos em observação participante: o que vem a ser participar nesse tipo de abordagem e quais os problemas éticos desse tipo de atividade. A participação, como é definida, rompe com os preceitos da "epistemologia da distância" que tudo faz para preservar a neutralidade do observador. Exige, em seu lugar, uma atitude de empatia que Montero descreve como "olhar horizontal que se reflete no olhar do outro" (2006, p. 206). Rompe, assim, com a ilusão da possibilidade do registro neutro.

Há, na literatura, diversos relatos sobre a dificuldade de manter essa postura híbrida de pesquisador e co-partícipe da situação vivida. Por exemplo, Donald Ball (1979) relata o episódio de um doutorando de uma universidade do centro-oeste americano que decidiu estudar gangues juvenis. Com este objetivo, passou a freqüentar um bar de uma cidade próxima que ele sabia, por observações anteriores, ser freqüentado por adolescentes delinqüentes. Em pouco tempo, conseguiu fazer contato com uma gangue e ser aceito como membro. A gangue em questão praticava atos de vandalismo assim como pequenos furtos para angariar fundos. $\mathrm{O}$ jovem pesquisador passou a participar das reuniões para planejamento desses furtos e, bastante perspicaz, começou a se preocupar com as falhas nesses planos - falhas suficientemente graves a ponto de poder levar à apreensão dos membros da gangue. Desejando manter seus sujeitos livres de envolvimento com as autoridades policiais, passou a fazer sugestões para sanar alguns dos problemas logísticos dos planos. Mas essa participação levou a conseqüências não antecipadas. Os membros da gangue resolveram delegar a responsabilidade pela organização dos furtos ao jovem pesquisador que se viu, portanto, diante de um novo dilema: tendo conseguido ser aceito pela gangue, viu-se na iminência de estar estudando uma gangue liderada por um jovem candidato a $\mathrm{PhD}$.

A literatura apresenta vários relatos sobre a dificuldade de ser aceito como participante na cena local. O caso da briga de galos relatado por Clifford Geertz (1978) é um exemplo clássico.

Geerz havia conseguido aprovação governamental para seu estudo de uma pequena comunidade tailandesa. Mas era visto com desconfiança pela população local, embora tratado com deferência. Certa noite, assistia juntamente com sua esposa, a uma briga de galos - atividade proibida no país - quando chegou a polícia. Todos os espectadores fugiram, inclusive Geertz e esposa. Não precisava; era estrangeiro e contava com apoio das autoridades governamentais. Na fuga, foi acolhido na casa de um morador local onde passou as horas conversando e tomando chá. Esse foi o ponto de reviravolta (Geertz, 1978) de suas relações com a comunidade, pois, a partir de então, consideraram-no aceito como participante legítimo.

O outro lado da participação é o comportamento ético presente nas situações de observação. Obviamente, a reflexão ética não é estática. O que definimos como ética hoje acompanha as complexas discussões sobre direitos de cidadania. Festinger, em 1950, certamente achava que seu estudo era ético. Mas hoje temos a obrigação de revelar quem somos, o que estamos fazendo e com que finalidade, assim como temos o compromisso de devolução dos resultados e, em certos casos, até mesmo o compromisso de co-construção explícita das interpretações.

\section{Midwest: A Observação na Emergente Psicologia Ambiental}

O terceiro estudo que escolhemos nesta busca de métodos de observação autóctones à Psicologia Social, reflete os esforços de ressignificação da observação qualitativa por meio de técnicas que exacerbam o rigor do registro e da interpretação. Trata-se de importante estudo que sustenta, até hoje, uma das tradições da Psicologia Ambiental que, no Brasil, tem um nicho na Universidade Federal do Rio Grande do Norte (por exemplo, Carneiro \& Bindé, 1997). Barker e Wright (1955/1971) informam, no prefácio do longo livro, que o estudo foi realizado entre 1947 e 1955 e publicado em 1955. Esgotado desde 1963, foi reimpresso apenas em 1971. Trata-se de uma 
descrição minuciosa do habitat ecológico de uma pequena comunidade do centro-oeste norte-americano onde Barker passa a se ocupar, prioritariamente, do desenvolvimento de técnicas apropriadas à Psicologia Ambiental e Wright, do registro e análise do comportamento infantil.

Diferentemente do estudo de Festinger et al. (1956), e em consonância com os atuais estudos de comunidades, Barker e Wright (1955/1971) partem do princípio de que os membros da comunidade devem estar claramente informados dos objetivos do estudo, dos métodos utilizados e dos problemas em estudo. Não apenas por considerações éticas; também como garantia de bom andamento do estudo que, por definição, se dá no tempo.

Há contribuições preciosas no livro para o registro de observações, com destaque para as noções de behavior setting, behavior patterns, behavior objects - que possibilitaram delimitar as zonas de observação desta pequena cidade de 707 habitantes. De forma resumida, os behavior episodes são as menores unidades de observação e concernem ao comportamento de uma única pessoa no seu contexto ecológico. Para um analista de discurso da tradição Bakhtiniana (por exemplo, Spink, 2004), tais episódios são semelhantes à noção de enunciados nas interanimações dialógicas. Traduzido para comportamentos, ao invés de discursos, são episódios que têm um direcionamento constante a um objetivo.

Entretanto, tais unidades moleculares, por si só, precisam ser entendidas em seu contexto de ação: os behavior setting - padrões de comportamento que se dão em um contexto específico: um local (como um restaurante) ou um evento (como a parada gay, ou o dia de Natal). Foi esta a unidade principal do estudo de Midwest.

Os behavior objects constituem a terceira unidade de estudo da metodologia desenvolvida e se referem ao meio não-psicológico da ação: escadas, livros, escovas de dente que não existem isoladamente dos behavior settings e dos behavior patterns. Existem em relação; são sinomórficos aos settings e padrões de comportamento. Vale ressaltar que Barker e Wright (1955/1971), com esta noção, antecipam certos desenvolvimentos recentes que buscam romper a dicotomia entre humanos e não-humanos, como faz Bruno Latour (2000) com a noção de actantes.

O desafio de Barker e Wright (1955/1971) era de fazer justiça à complexidade e riqueza dos habitat psicológicos presentes em uma comunidade e, paralelamente, ater-se aos princípios que pautavam, então, a pesquisa psicossocial: observar sem destruir o habitat natural. Claro que, desde então, muito ocorreu na reflexão sobre a relação entre pesquisador e o fenômeno pesquisado, sendo corrente, hoje, a compreensão de que o pesquisador, inevitavelmente, é co-autor desse habitat. Mas, para os fins a que me propus neste artigo, a importância do estudo de Midwest é a afirmação de que a metodologia básica de um field station (uma estação de campo) deve ser a observação direta de comportamento no habitat psicológico. Porém, para Barker e Wright, que são afinal homens de sua época, tais observações têm que prover medidas quantitativas das características ambientais, de modo que se possam comparar as condições psicológicas de vida em uma determinada comunidade com as de outras comunidades. Com essa finalidade, os autores desenvolveram uma série de instrumentos de registro para: (a) a descrição densa e detalhada de um segmento longo de comportamento de uma determinada criança por um observador treinado (specimen records); (b) a catalogação e descrição dos behavior settings da comunidade (behavior setting survey) e (c) a identificação e análise dos objetos presentes no habitat psicológico de uma pessoa no curso do dia (behavior object inventory).

O uso de observações minuciosas, de verificação por pares para validar escolhas e classificações, da ênfase em quantificação, torna difícil a leitura das 500 páginas de relatos de settings, padrões de comportamento e interações sociais nesses espaços de sociabilidade. Certamente, há contribuições valiosas para quem se propõe a pesquisar no cotidiano e seria um desafio trazê-las para a contemporaneidade. Mas, há também diferenças importantes para quem não tem uma comunidade específica como foco; para quem quer pesquisar os fluxos de comportamentos que se dão em espaços públicos de convivência, como por exemplo, a rua.

\section{Retomando a Pesquisa em Espaços Públicos de Convivência: Reflexões sobre Olhar e Linguagem}

Tal como nos estudos precursores, esse cotidiano fugaz clama pelo uso de métodos não interferentes (unobstrusive) em pesquisa social, expressão cunhada por Webb em 1966 (Webb et al., 1981) para referir-se aos dados obtidos por processos que não envolvem a coleta direta de informações das pessoas que fazem parte da pesquisa; porém, em um contexto epistemológico diverso. Ressignificadas à luz das teorizações pós-modernas sobre conhecimento situado (por exemplo, Haraway, 1995), moldadas pelas vertentes interpretativas e culturalistas de ação social (Geertz, 1978) e retomadas como formas de superar os impasses éticos de pesquisa em seres humanos, as formas não interferentes de coleta de dados assumiram novas conotações: a observação não-participante, a análise de textos e documentos e os estudos de mídia passaram a ter um lugar cada vez mais proeminente na pesquisa em Psicologia Social.

Nessas observações itinerantes em espaços públicos de convivência e nas observações mais detalhadas em diferentes behavior settings, quando pesquisamos no cotidiano, nos posicionamos como membros competentes desses lugares e territórios, que compartilham códigos e expectativas e são, portanto, capazes de desenvolver o que Gar- 
finkel (1967/1984) denomina compreensão compartilhada (common understanding). Segundo o autor, "Os estudos etnometodológicos analisam as atividades cotidianas como métodos usados pelos membros para tornar essas mesmas atividades visivelmente-racionais-e-relatáveis-para-todosos-propósitos-práticos, ou seja, accountable, como organizações de atividades cotidianas corriqueiras" (Garfinkel, p. vii).

Em suma, em uma releitura da abordagem de Garfinkel (1967/1984), consideramos que, ao pesquisar no cotidiano, nos posicionamos como membros da comunidade e, como tal, capazes de interpretar as ações que se desenrolam nos espaços e lugares em que se dará a pesquisa porque somos parte desta comunidade e compartilhamos normas e expectativas que nos permitem pressupor uma compreensão compartilhada. Essa compreensão compartilhada repousa na indicialidade (ou indexalidade). Estamos aptos a entender as expressões indexicais (indexical expressions) e as ações indexicais (indexical actions) - os indícios de sentido, freqüentemente incompletos, que adquirem sua plena capacidade na comunicação - porque somos capazes de considerar a parte (a enunciação e a ação) em relação ao todo (o contexto em que se dá a ação/interação).

Mas, como não poderia deixar de ser, as observações no cotidiano nos apresentam a problemática do olhar e sua relação com a linguagem. Contamos hoje com um arsenal técnico que possibilita registros de cenas cotidianas: mini-gravadores para descrever o que vemos; câmeras e filmadoras digitais para registrar imagens e movimentos. Mas de posse desses registros, temos que decidir como proceder: por exemplo, transformá-los em linguagem numérica (quantas "bitucas" de cigarro na rua, quantas pessoas comprando maços de cigarros, quantas fumando nesses espaços públicos) ou textual, descrevendo episódios de comportamento em diferentes behavior settings. Podemos, ainda, optar por deixar as imagens falarem por si. Encerro, assim, com uma observação de Susan Sontag (2004) sobre a transformação do significado de fotos, segundo o contexto de uso e a presença ou ausência de legendas. Diz ela:

Como cada foto é apenas um fragmento, seu peso moral e emocional depende do lugar em que é vista: assim, as fotos de Minamata tiradas por Smith parecerão diferentes numa cópia de contato, numa galeria, numa manifestação política, num arquivo policial, numa revista de fotos, numa revista de notícias comuns, num livro, na parede de uma sala de estar. Cada uma dessas situações sugere um uso diferente para as fotos, mas nenhuma delas pode assegurar seu significado.

Os moralistas que amam fotos sempre esperam que as palavras salvem a imagem (o caminho inverso ao do curador de um museu que, a fim de transformar em arte a obra fotojornalista, expõe as fotos sem as legendas originais) (Sontag, 2004, p. 122, 123).

\section{Notas}

1 A pesquisa conta com o apoio do CNPq.

\section{Referências}

Ball, D. W. (1979). Self and identity in the context of deviance: The case of criminal abortion. In M. Wilson (Ed.), Social and Education research in action: A book of readings (pp.189-217). London: Longman/The Open University Press.

Barker, R. G., \& Wright, H. F. (1971). Midwest and its children: The Psychological ecology of an American town. Hartford, CT: Archon Books. (Original publicado em 1955)

Brandão, C. R. (Ed.). (1981). Pesquisa participante. São Paulo, SP: Brasiliense.

Burgess, R. G. (1982). Approaches to field research. In R. G. Burgess (Ed.), Field Research: A sourcebook and field manual (pp. 1-14). London: George Allen \& Unwin.

Carneiro, C., \& Bindé, P. J. (1997). A Psicologia Ecológica e o estudo dos acontecimentos da vida diária. Estudos de Psicologia, 2, 277-285.

De Certeau, M. (1996). A invenção do cotidiano. Petrópolis, RJ: Vozes.

Denzin, N. (1970). The research act. Chicago: Aldine.

Festinger, L., Riecken, H. W., \& Schachter, S. (1956). When prophecy fails: A social and psychological study of a modern group that predicted the destruction of the world. New York: Harper Torchbooks.

Fals Borda, O. (1981). Aspectos teóricos da pesquisa participante: Considerações sobre o significado e o papel da ciência na participação popular. In C. R. Brandão (Ed.), Pesquisa participante (pp. 42-62). São Paulo, SP: Brasiliense.

Freire, P. (1974). Pedagogia do oprimido. Rio de Janeiro, RJ: Paz e Terra.

Garfinkel, H. (1984). Studies in ethnomethodology. Cambridge, UK: Polity Press. (Original publicado em 1967)

Geertz, C. (1978). A interpretação das culturas. Rio de Janeiro, RJ: Jorge Zahar.

Haraway, D. (1995). Conocimientos situados: La cuestión científica en el feminismo y el privilegio de la perspectiva parcial. In D. Haraway. Ciência, cyborgs e mujeres: La reinvencion de la naturaleza (pp. 313-346). Valencia, España: Cátedra.

Heller, A. (1972). O quotidiano e a história. Rio de Janeiro, RJ: Paz e Terra.

Jahoda, M., Lazarsfeld, P., F., \& Zeisel, H. (2003). Marienthal: The sociography of an unemployed community. New Brunswick, Canada: Transaction.

Latour, B. (2000). Ciência em ação. São Paulo, SP: Editora da Universidade Estadual Paulista.

Montero, M. (Ed.). (1994). Psicologia Social Comunitária. Guadalajara, México: Universidad de Guadalajara.

Montero, M. (2006). Hacer para transformar: El método en la Psicología Comunitaria. Buenos Aires, Argentina: Paidós.

Sontag, S. (2004). Regarding the pain of others. New York: Picador. Spink, M. J. (2004). Linguagem e produção de sentidos no cotidiano. Vol. 1: Debates Contemporâneos em Psicologia Social. Porto Alegre, RS: Editora da Pontifícia Universidade Católica do Rio Grande do Sul.

Webb, E. J., Campbell, D. T., Schwartz, R. D. D., Sechrest, L., \& Grove, J. B. (1981). Nonreactive measures in the social sciences (2nd ed.). Boston: Houghton Mifflin. 
Mary Jane P. Spink é professora titular da Pontifícia Universidade Católica de São Paulo. Doutora em Psicologia Social pela London School of Economics and Political Science, Universidade de Londres. Pesquisadora do CNPq, autora de livros e artigos versando sobre saúde coletiva, risco como estratégia de governamentalidade na contemporaneidade e práticas discursivas do cotidiano. Endereço para correspondência: Rua Landgraft, $62-$ CEP 04638-040, São Paulo, SP.

mjspink@pucsp.br
Pesquisando no cotidiano: recuperando memórias de pesquisa em Psicologia Social

Mary Jane P. Spink

Recebido: 29/07/2006

$1^{\text {a }}$ revisão: 25/09/2006

Aceite final: 22/10/2006 